$$
\begin{array}{cr}
\text { GA-A22717 } \\
\text { CONF }-97 / 065-- \\
\text { OVERVIEW OF THE DIII-D } & \text { RECEIVE } \\
\text { PROGRAM COMPUTER SYSTEMS } & \text { JAN } 261998 \\
\text { OS TI } & \\
\text { B.B. MCHARG, JR. } &
\end{array}
$$

\section{OVERVIEW OF THE DIII-D PROGRAM COMPUTER SYSTEMS}

\author{
by
B.B. McHARG, JR.
}

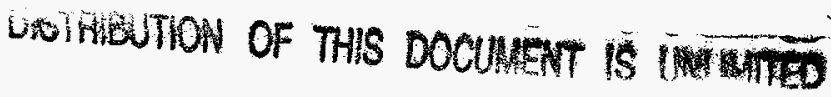

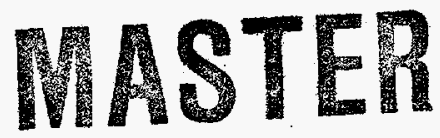

NOVEMBER 1997 


\section{DISCLAIMER}

This report was prepared as an account of work sponsored by an agency of the United States Government. Neither the United States Government nor any agency thereof, nor any of their employees, make any warranty, express or implied, or assumes any legal liability or responsibility for the accuracy, completeness, or usefulness of any information, apparatus, product, or process disclosed, or represents that its use would not infringe privately owned rights. Reference herein to any specific commercial product, process, or service by trade name, trademark, manufacturer, or otherwise does not necescarily constitute or imply its endorsement, recommendation, or favoring by the United States Government or any agency thereof. The views and opinions of authors expressed herein do not necessarily state or reflect those of the United States Government or any agency thereof. 


\section{DISCLAIMER}

Portions of this document may be illegible electronic image products. Images are produced from the best available original document. 


\title{
OVERVIEW OF THE DIII-D PROGRAM COMPUTER SYSTEMS
}

\author{
by \\ B.B. MCHARG, JR.
}

This is a preprint of a paper to be presented at the 17th IEEE/NPSS Symposium on Fusion Engineering, October 6-11, 1997, San Diego, California and to be published in the Proceedings.

\author{
Work supported by \\ the U.S. Department of Energy \\ under Contract No. DE-AC03-89ER51114
}

GA PROJECT 3466

NOVEMBER 1997 


\title{
Overview of the DIII-D Program Computer Systems*
}

\author{
B.B. McHarg, Jr. \\ General Atomics \\ P.O. Box 85608, San Diego, California 92186-9784
}

\begin{abstract}
Computer systems pervade every aspect of the DIII-D National Fusion Research program. This includes real-time systems acquiring experimental data from data acquisition hardware; cpu server systems performing short term and long term data analysis; desktop activities such as word processing, spreadsheets, and scientific paper publication; and systems providing mechanisms for remote collaboration. The DIII-D network ties all of these systems together and connects to the ESNET wide area network. This paper will give an overview of these systems, including their purposes and functionality and how they connect to other systems. Computer systems include seven different types of UNIX systems (HP-UX, REALIX, SunOS, Solaris, Digital UNIX, Ultrix, and IRIX), OpenVMS systems (both VAX and Alpha), MACintosh, Windows 95, and more recently Windows NT systems. Most of the network internally is ethernet with some use of FDDI. A T3 link connects to ESNET and thus to the Internet. Recent upgrades to the network have notably improved its efficiency, but the demand for bandwidth is ever increasing. By means of software and mechanisms still in development, computer systems at remote sites are playing an increasing role both in accessing and analyzing data and even participating in certain controlling aspects for the experiment. The advent of audio/video over the internet is now presenting a new means for remote sites to participate in the DIII-D program.
\end{abstract}

\section{INTRODUCTION}

The DIII-D tokamak is a fusion research experiment operated by General Atomics (GA) under contract with the Department of Energy. This experiment is dedicated to the study of the properties of high temperature plasmas approaching fusion reactor-like conditions. Results of these experiments are particularly applicable to next generation fusion devices. DIII-D is a pulsed experiment that takes "shots" of 5-10 s duration about once every $10 \mathrm{~min}$, with $40-50$ shots per operating day.

The computer systems in use at GA pervade every aspect of the DIII-D program. These aspects include:

1. Real time systems controlling the experiment, heating systems, and diagnostics; and systems acquiring experimental data from data acquisition hardware.

2. CPU server systems performing short term and long term data access and data analysis.
3. Desktop activities such as word processing, spreadsheets and scientific paper publication.

4. Systems providing mechanisms for remote collaboration and the dissemination of information over the world wide web.

All aspects of the DIII-D computer systems are tied together by the DII-D network which thus provides local area access as well as wide area access via connection to the Energy Sciences Network (ESNET).

The purpose of this paper is to give an overview of all the computer systems and their uses including the various aspects mentioned above as well as the network.

\section{OVERVIEW}

There are several key features of the DIII-D computer systems which include:

1. Highly distributed computer network with distributed data access [1].

2. Connection to the wide area network.

3. Integration of a variety of hardware and software platforms particularly for the control/data acquisition functions.

Fig. 1 illustrates the variety of computer systems in use. These systems reside either at the DIII-D facility itself, in the DIII-D office buildings (about one mile away), or in the DIII-D computer center adjacent to the office buildings. This figure is intended as a logical as opposed to a physical diagram. The network switches indicated actually distribute the network into many different segments. The node names are to the left of the vertical line. To the right is the computer type, operating system, and basic function. Systems can be grouped according to general functions:

1. Control systems are used primarily to control various aspects of the experiment.

2. Diagnostics/Data Acquisition systems are used to acquire information from the experiment.

3. Real Time Data Processing/Analysis are systems

\footnotetext{
*Work supported by U.S. Department of Energy under Contract No. DE-AC03-89ER51114.
} 


\section{DIII-D FUSION COMPUTER SYSTEMS}

Control Systems

I
N
S
T
R
U
M
I N
I T
A
T
I
O
N

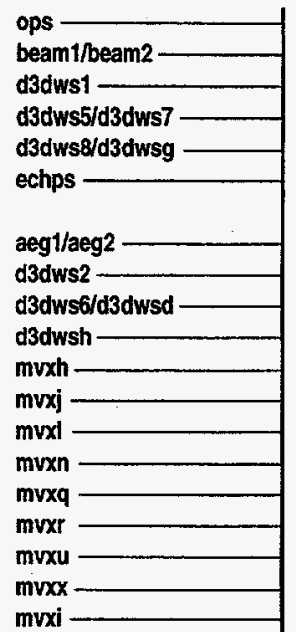

waybak

cads
d3dws4-
helios
cyclop
vaxs
mvxs
muxv

Modcomp, Realix, tokamak control

Modcomp, Realix, Neutral Beam control

Sun, Solaris, New plasma control

Sun, SunOs, plasma control

Sun, Solaris, ICH control

DEC Alpha, DEC UNIX, ECH control

Diagnostics/Data Acquisition

Modcomp, Realix, general DAO

Sun, SunOS, Langmuir probe

Sun, SunOS, CER

HP, HP-UX, Thomson scaltering

MicrovaX, VMS, pellet injector

MicroVAX, VMS, Lithium beam

MicroVAX, VMS, Langmuir probe

MicroVAX, VMS, spectrometer

MicroVAX, VMS, Thomson scattering

MicroVAX, VMS, reflectometer

MicroVAX, VMS, spread diagnostic

MicroVAX, VMS, CER

VAXstation, VMS, Langmuir probe

DEC Alpha, VMS, BES

Real Time Data Processing/Analysis/Miscellaneous

Sun , Solaris, cad/cam

HP, HP-UX, Thomson Scattering

HP, HP-UX, real time processing

SGI, IRIX, audio/video

DEC VAX, VMS, data management/archiving

VAXstation, VMS, VAXcluster control

VAXstation, VMS, MFT calculation

Ethernet $(10 \mathrm{Mb} / \mathrm{s})$

Alantec network switch

FDDI (100 Nb/s)

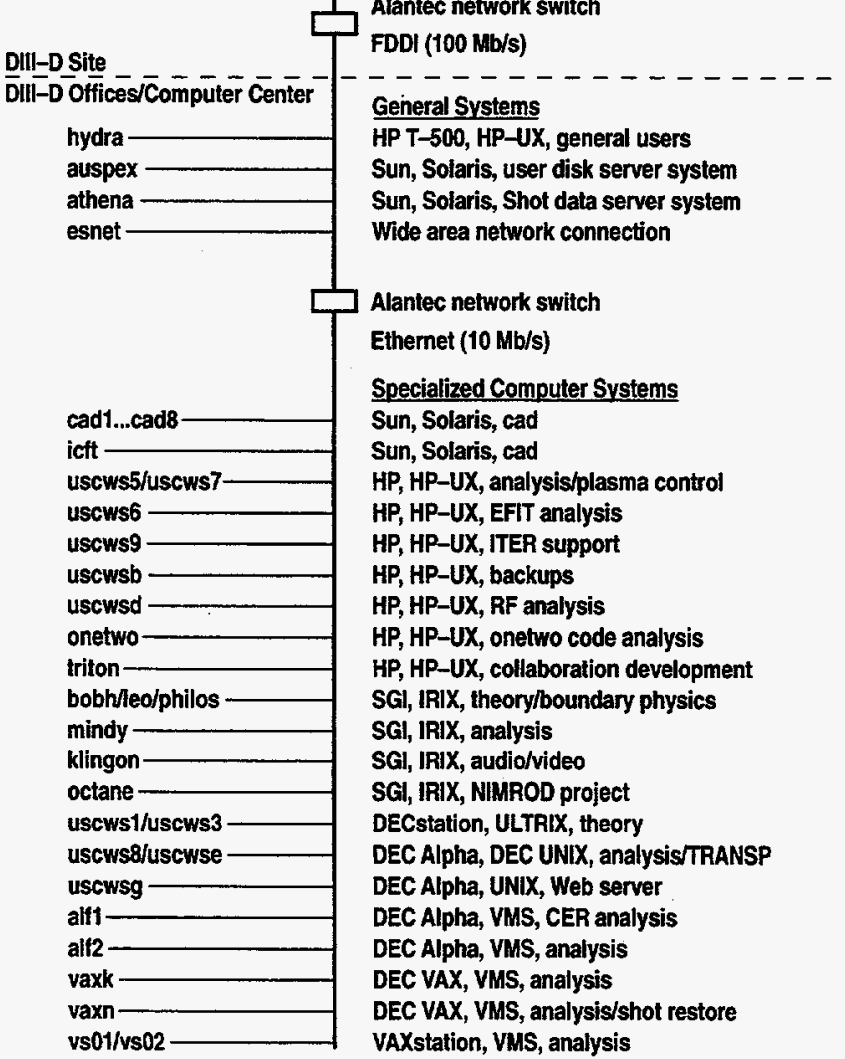

Fig. 1. Logical diagram of the DIII-D computer system.

dedicated to the processing of data in real time which also includes systems used for $\mathrm{A} / \mathrm{V}$ broadcasting and communications.
4. The general systems allow users to run programs in real time or at any other time and to provide general computer user services and data availability.

5. The specialized systems in the office buildings are generally dedicated to specific purposes such as running specific analysis codes like EFIT, ONETWO, etc.

Most of the network is currently Ethernet $(10 \mathrm{Mb} / \mathrm{s})$. However there is an FDDI $(100 \mathrm{Mb} / \mathrm{s})$ link between the experimental facility and the office buildings. Certain other computers are also connected to FDDI. In the future, more systems are expected to be migrated to either FDDI or Fast Ethernet to provide for the ever increasing needs of bandwidth. The connection to ESNET is via a T3 line (45 $\mathrm{Mb} / \mathrm{s})$.

There are other computers connected to the network that are not shown on this diagram. These include approximately 350 desktop computers (MACintosh's running MAC OS and PC's running Windows 3.1, 95, or NT). Although most of these are used for purposes such as word processing, spreadsheets, graphics, and publications, there are some which are used to control diagnostics, acquire data, and perform data analysis.

\section{CONTROL SYSTEMS}

When the predecessor of DIII-D (Doublet III) began operation in the late 70's, their was one control system and one data acquisition system that were based on computers from MODCOMP which ran a real time operating system. Over time those systems grew to number nine and were used for tokamak control, general data acquisition, neutral beam control, and some data analysis [2]. These systems continued to be used until the mid 90's, but have now all been replaced by new computer systems, also from MODCOMP, running a version of the UNIX operating system called REALIX $[3,4,5]$. The tokamak control system (ops) and the neutral beam control systems (beam1/beam2) make use of a commercial control system software package called AccessWare which was interfaced to CAMAC by GA personnel $[6,7]$.

Of particular importance to the success of the tokamak is the plasma control system (PCS) which is used to shape the plasma [8]. This system has utilized a SUN computer running SunOS for many years, but an upgrade is currently in progress to a faster SUN computer running Solaris. The PCS software was developed at GA and much of it uses Interactive Data Language (IDL) software.

Two other important plasma heating mechanisms are electron cyclotron heating (ECH) and ion cyclotron heating (ICH). Two SUN Solaris systems are used for the ICH control (and some data acquisition) using Labview 
software. The ECH system uses control software from Vista Control Systems.

\section{DIAGNOSTICS/DATA ACQUISITION}

The biggest driving factor to upgrade the general data acquisition computers to a modern platform was the ever increasing quantities of data being acquired due to more diagnostics being put onto the tokamak, longer pulse lengths, and faster digitization rates. A point had been reached by the early 90 's where the time for data acquisition was limiting the shot cycle. The newer aeg1 computer is now acquiring over 100 Megabytes per shot from two CAMAC highways with a very comfortable margin for the shot cycle. In the future, a third CAMAC highway may be added, or the spare system, aeg2, may be brought into service for data acquisition.

The aeg1 computer acquires data from a variety of diagnostics including: magnetics, $\mathrm{CO} 2$ interferometer, photodiodes, soft $\mathrm{x}$-ray, microwave radiometer, electron cyclotron emission, as well as many others. Most of the software for the data acquisition system was developed by GA personnel.

There are many other diagnostics connected to separate computer systems including Thomson scattering, charge exchange recombination, Langmuir probes, spectrometers, and reflectometers. These diagnostics often have special needs which thus require a separate system. When all the diagnostics are added together along with aeg1, the quantity of data acquired from a shot has reached as high as 219.1 Megabytes, while averaging over 200 Megabytes. These numbers are only expected to increase.

The various diagnostics are spread over a variety of computer systems. Historically these were MicroVAX systems running the VMS operating system. More recently many UNIX systems (SUN or HP) have been used for diagnostics. Some of these use software developed by the users themselves and in some cases commercial software is used. Of particular importance is that the DIII-D program can accommodate a wide variety of computer systems. A standard set of GA software is used for communication and for creating shot data files and migrating the data for archiving and data management.

\section{REAL TIME DATA PROCESSING/ANALYSIS/MISCELLANEOUS}

During operations, physicists are logged onto many different computer systems displaying and analyzing data in real time. A few systems at DIII-D are specifically dedicated to this purpose or have other specific purposes. One HP computer is used for the coordination and analysis of Thomson Scattering data which is one of the most critical diagnostics for the tokamak. Another HP workstation is for use by the session leader of the day and associates for more dedicated compute cycles. A VAXstation produces a graphical display of the equilibrium fit (MFIT). A VAX computer (vaxs) is the central coordinator of data gathering from the various diagnostics systems. All new data is migrated to vaxs, and archiving of all data also takes place on this system.

As a national facility, DIII-D is becoming ever more important for remote collaboration. Recent studies are just beginning to facilitate such capabilities [9]. One aspect of this is an SGI computer used for broadcasting audio and video from the control room (as well as morning status meetings) using MBONE tools to broadcast over the internet. This is also broadcast from a MACintosh using CU-SeeMe software. Work in this area is expected to increase in coming years as computer systems at remote sites are playing an ever increasing role both in accessing and analyzing data and even participating in certain controlling aspects of the experiment.

\section{GENERAL USER SYSTEMS}

The central system used by general users for computer access and data analysis is a three cpu HP T-500. This system provides compute cycles for data access, data analysis, and code development for general users. During operations this system is very heavily used, and there are plans to upgrade it to a T-600 in the near future, thus providing 4 times more computational capacity. This system is connected to an Auspex disk server. The home directories of all users for the HP computers are contained on the Auspex. Anyone logging into any of the HP computers thus uses the same home directory. The Auspex is also used for the storage of processed data results.

The HP T-500 used to be used for the serving of shot data to users from locally attached disks. However this function has just been moved to a new shot server system. This system has 100 gigabytes of usable RAID disk capacity dedicated to shots which is about 2.5 times what was available on the T-500. Approximately 2000 shots can now be online. It is planned to also connect a mass storage system to the shot server in the near future to thus provide unattended and more rapid shot data restoration.

\section{SPECIALIZED DATA ANALYSIS SYSTEMS}

There are numerous other computers generally dedicated to specific purposes with limited user accounts. Their purposes include data analysis, theoretical modeling, backups, data restoration, web serving, and audio/video communications.

Vaxn is a general user computer, and there are some codes which have not been converted to run on a UNIX cpu. Thus they are still run on the VAX. This VAX is also particularly important as shot data is initially restored to 
the VAX and then later transferred to the shot server system. The existing physics database system, S1032, also only resides on the VAXcluster. The VAXcluster consists of two VAX computers (vaxn/vaxk) and two VAXstations. There are also two DEC Alphas in the cluster, but they have their own system disks. It is planned to replace the old VAX computers and VAXstations with a single DEC Alpha server. Thus all of the VMS computers will then be Alphas.

A relatively new addition is the DEC Alpha running DEC UNIX to provide a web server. This function was previously done on a MACintosh but the needs of the website now require a more robust system.

The SGI computer, klingon, is frequently used for MBONE audio/video communications. Various meetings are more often now beginning to be broadcast, as well as private meetings. Recent meetings broadcast have included the DIII-D physics brainstorming session in January, 1997, the FESAC meeting in January, 1997, and the CMOD/DIII-D tokamak workshop in July, 1997.

\section{FUTURE PLANS}

As DIII-D is now called a national facility, a number of upgrades are required to facilitate this designation. Currently planned upgrades for the computer facilities on DIII-D include:

1. Upgrading existing network wiring in the office buildings so that it will be compatible with higher network speeds.

2. Migrating more computer components to $100 \mathrm{Mb} / \mathrm{sec}$ network speeds.

3. Replacing the old VAXcluster VAX and VAXstation computers with a modern DEC Alpha VMS server.

4. Upgrading the HP T-500 to a T-600 to provide four times more computational cycles.

5. Upgrading the Auspex disk server to expand capacity.

6. Replacing/upgrading older workstations to more modern platforms.

7. Adding a mass storage system to provide both unattended and more rapid restoration of data, thus providing a higher quality of data availability.
8. Integrating the MACintosh/PC platforms into the computer environment for purposes such as data acquisition, data access and data analysis.

9. Improving communication and access methods to facilitate remote collaboration.

10. Adding a new physics database system.

The flexibility and distributed nature of the computer systems has enabled DIII-D to provide computer services not only to local users, but also to the wider area fusion community. Upgrading of these facilities will help complement the role of DII-D as a national facility.

\section{REFERENCES}

[1] B. McHarg, "Access to DIII-D data located in multiple files and multiple locations," in Proc. 15th Symp. on Fusion Engineering, p. 123, 1993.

[2] B. McHarg, "Real-time diagnostic data acquisition system for the Doublet III tokamak fusion experiment," in Proc. IEEE Transactions on Nuclear Science, vol. 30, p. 3787, 1983.

[3] P. Henline, "Use of open systems for control, analysis, and data acquisition of the DIII-D tokamak," in Proc. 15th Symp. on Fusion Engineering, p. 127, 1993.

[4] P. Henline, "Improved operating scenarios of the DIII-D tokamak as a result of the addition of UNIX computer systems," in Proc. 16th Symp. on Fusion Engineering, 1995.

[5] B. McHarg, "Conversion of the central DIII-D data acquisition system to a UNIX based platform," unpublished, 1995.

[6] B. Penaflor, B. McHarg, and D. Piglowski, "Software development on the DIII-D control and data acquisition computers", these proceedings.

[7] D. Piglowski, B. Penaflor, J. Phillips, "Use of the accessware interface/database software in the neutral beam control systems used by the DIII-D tokamak", these proceedings.

[8] B. Penaflor, J. Ferron, M. Walker, "A structured architecture for advanced plasma control experiments," unpublished.

[9] B. McHarg, T. Casper, S. Davis, D. Greenwood, "Tools for remote collaboration on the DIII-D national fusion facility," presented at the IAEA Technical Committee Meeting on Data Acquisition and Management for Fusion Research, Garching, Germany, July, 1997. 